\title{
Adrenergic Transmission Facilitates Extinction of Conditional Fear in Mice
}

\author{
Christopher K. Cain, ${ }^{1}$ Ashley M. Blouin, ${ }^{1}$ and Mark Barad ${ }^{2,3}$ \\ ${ }^{1}$ Interdepartmental Program in Neuroscience, ${ }^{2}$ Department of Psychiatry and Biobehavioral Sciences, Neuropsychiatric Institute, \\ and Brain Research Institute, UCLA, Los Angeles, California 90095, USA
}

\begin{abstract}
Extinction of classically conditioned fear, like its acquisition, is active learning, but little is known about its molecular mechanisms. We recently reported that temporal massing of conditional stimulus (CS) presentations improves extinction memory acquisition, and suggested that temporal spacing was less effective because individual CS exposures trigger two opposing processes: (1) fear extinction, which is favored by CS massing, and (2) fear incubation (increase), which is favored by spacing. We here report the effects of manipulating the adrenergic system during massed or spaced CS presentations in fear-conditioned mice. We administered yohimbine $(5 \mathrm{mg} / \mathrm{kg})$, an $\alpha_{2}$-receptor antagonist, or propranolol $(10 \mathrm{mg} / \mathrm{kg})$, a $\beta$-receptor antagonist, systemically prior to CS presentation sessions and recorded both short- and long-term changes in conditional freezing. Yohimbine treatment facilitated extinction of both cue and context fear with massed protocols. When given before spaced CS presentations, propranolol led to a persistent incubation of cue fear, whereas yohimbine led to persistent extinction, compared with vehicle-treated animals, which showed no change in fear. These results suggest that norepinephrine positively modulates the formation of fear extinction memories in mice. They also provide clear evidence that spaced CS presentations trigger both fear-reducing (extinction) and fear-increasing (incubation) mechanisms.
\end{abstract}

Accurate prediction of environmental danger is vital for survival and involves learning contingent associations between nonthreatening cues and aversive stimuli. Pavlovian, or classical, fear conditioning has long been an important model of associative learning and of the etiology of human anxiety (Watson and Rayner 1920; Eysenck 1979; Wolpe and Rowan 1988). Temporal pairing of a neutral conditional stimulus (CS) with an aversive unconditional stimulus (US) generates robust conditional fear responses upon subsequent presentations of the CS in experimental animals, including mice. Fear in mice consists of a cassette of responses similar to those of human fear and anxiety, including increases of blood pressure and heart rate, changes in respiration, increased startle responses, and behavioral freezing (Blanchard and Blanchard 1969; Bolles and Fanselow 1980; Davis 1992; LeDoux 2000). Extinction of such conditional fear, the progressive weakening of the conditioned response by repeated presentations of CS without the US, has served as the explicit model for behavior therapy of human anxiety disorders, one of the most effective of psychotherapies (Wolpe 1969; Craske 1999). Considerable evidence indicates that extinction, like fear acquisition, is active learning, which inhibits rather than erases the original association. For example, even completely extinguished fear can return spontaneously after the passage of time (Baum 1988 ) or be "reinstated" by presentations of US alone (Rescorla and Heth 1975). Furthermore, conditional fear is "renewed" when the CS is presented in a context different from that in which extinction took place (Bouton and King 1983). Like many other forms of learning and synaptic plasticity, including fear acquisition, extinction depends on NMDA-type glutamate receptor activity and on MAP kinase (Falls et al. 1992; Baker and Azorlosa 1996; Lu et al. 2001). However, we have recently shown that extinction differs from fear acquisition at the molecular level, because extinction, but not acquisition or expression, of condi-

\footnotetext{
${ }^{3}$ Corresponding author.
}

E-MAIL mbarad@mednet.ucla.edu; FAX (310) 267-0040.

Article and publication are at http://www.learnmem.org/cgi/doi/10.1101/ Im.71504. tional fear depends on L-type voltage-gated calcium channels (Cain et al. 2002; Frankland et al. 2002). Such differences from other forms of learning promise to point to mechanisms of particular interest for understanding brain function in inhibitory learning and psychotherapy.

One very general excitatory learning rule is that memory is stronger when training trials are "spaced" or distributed in time (Ebbinghaus 1885/1913; Carew and Kandel 1973; Fanselow and Tighe 1988; Fanselow et al. 1993; Tully et al. 1994; Kogan et al. 1997; Freudenthal et al. 1998; Barela 1999; Josselyn et al. 2001). We recently reported that, in contrast to most acquisition learning, more short- and long-term extinction of cue fear followed temporally massed CS presentations than spaced presentations (Cain et al. 2003). The pattern of the behavioral data during the CS presentations in those experiments led us to hypothesize that CS presentations initiate two opposing mechanisms: (1) a fearreducing mechanism (extinction) favored by CS massing, and (2) a fear-increasing mechanism (incubation) favored by CS spacing. Although no persistent increases in fear were observed in these experiments, mice given spaced CS presentations failed to extinguish, despite receiving many nonreinforced CS presentations.

We here report experiments examining the role of adrenergic neurotransmission in the extinction and incubation of conditional fear. Two considerations inspired these studies. First, the adrenergic system has long been associated with fear. In the early twentieth century, Walter B. Cannon suggested that it might orchestrate the fight or flight response (Cannon 1963). Lesions of the major brain nucleus of adrenergic cell bodies, the locus coeruleus, ablate fear reactions of monkeys (Huang et al. 1975). Conversely, stimulation near that structure generates fearful behavior in monkeys (Redmond Jr. et al. 1976). Consistent with this association, norepinephrine is released in the amygdala after many aversive stimuli, including footshock, and contributes to the expression of fear and anxiety in rats (Tanaka et al. 2000). Other studies indicate that adrenergic neurotransmission enhances strengthening at some synapses (Sarvey et al. 1989; Huang and Kandel 1996), and is crucial to the acquisition (Schulz 
et al. 2002) and consolidation of emotional memories in animals (Izquierdo and Medina 1995; Ferry and McGaugh 1999; Cahill et al. 2000) and humans (Cahill et al. 1994; Nielson and Jensen 1994). Second, adrenergic hyperactivity has been implicated in human anxiety disorders (Jefferson 1996; Southwick et al. 1999). Propranolol, which blocks $\beta$-adrenergic receptors, is a standard and effective prophylactic treatment for specific social phobia or performance anxiety (Jefferson 1996). Conversely, yohimbine, which blocks autoinhibitory $\alpha_{2}$ adrenergic receptors, is anxiogenic in humans. Yohimbine induces panic attacks in panic disorder patients, and both panic attacks and flashbacks in posttraumatic stress disorder patients (Charney et al. 1992; Southwick et al. 1993). On the basis of these studies, we hypothesized that adrenergic neurotransmission would tend to strengthen fear and retard extinction. Instead, our data indicate that adrenergic neurotransmission promotes extinction and blocks fear incubation, in a modulatory manner. The data also support the hypothesis that nonreinforced CS presentations induce both fear extinction and fear incubation mechanisms.

\section{RESULTS}

\section{Massed Extinction and Adrenergic Manipulation}

We investigated the role of adrenergic neurotransmission in extinction of context and cue fear. We designed our training protocols to yield freezing above $50 \%$ in retention controls to maximize our ability to detect significant extinction during and fol- lowing massed CS exposure. Mice were trained with two pairings of a 2-min 80-dB white noise CS coterminating with a 2-sec footshock $(0.7 \mathrm{~mA}, 2 \mathrm{~min}$ ITI), in a drug-free state, and training, extinction, and retention testing were done a day apart, to allow for memory consolidation. Moderately high doses of yohimbine $(5 \mathrm{mg} / \mathrm{kg})$, propranolol $(10 \mathrm{mg} / \mathrm{kg})$, or vehicle were injected 20 min prior to the extinction session. Five separate experiments were conducted with cue fear using $0,5,10,20$, or 30 massed 2-min CSs (5 sec ITI) to induce extinction. Four separate experiments were conducted with context fear, examining the effect of $0,20,40$, or 60 total minutes of exposure to the feared context (in a continuous block, no ITI). We have previously proposed that massed CS presentations behaviorally isolate extinction from incubation (Cain et al. 2003), and we used massed CS presentations in these first experiments to examine the role of the adrenergic system specifically in extinction.

Long-term extinction was assessed by presenting all mice with a single CS in the extinction context on Day 3. In all the cue fear experiments (Fig. 1), freezing prior to the Day 3 CS presentation was low for all groups, indicating that context generalization, sensitization, and second-order conditioning were not significant factors during the final test. When groups of mice were injected with vehicle, yohimbine, or propranolol on Day 2, but not exposed to any CSs, there were no differences in freezing at the final test on Day $3\left(F_{(2,21)}=1.79, p=0.19\right.$; Fig. $\left.1 \mathrm{~A}\right)$, suggesting the drug injections did not interfere with cue fear consolidation or its recall a day later. After CS presentations on Day 2, freezing differed between the groups during the final tests: five $\operatorname{CSs}\left(F_{(3,28)}=3.97\right.$, $p<0.05)$; 10 CSs $\left(F_{(3,28)}=2.36, p=0.09\right)$; $20 \mathrm{CSs}\left(F_{(3,28)}=8.04, p<0.01\right)$; $30 \mathrm{CSs}$ $\left(F_{(3,28)}=6.59, p<0.01\right)$. As expected, more CS presentations on Day 2 generated greater long-term extinction on Day 3. Vehicle-treated mice that received 20 or 30 CSs on Day 2 froze significantly less than nonextinguished RC mice ( $p$-values $<0.05$; Fig. $1 \mathrm{D}, \mathrm{E})$, whereas those receiving five or $10 \mathrm{CSs}$ showed no long-term extinction ( $p$-values $>0.05$; Fig. 1B,C). Mice treated with yohimbine prior to the Day 2 CS presentations froze significantly less than vehicle-treated mice when only five CSs were given on Day 2 ( $p<0.05$; Fig. 1B). Propranolol had no significant effect on long-term extinction. Mice treated with propranolol never differed in their final freezing relative to mice extinguished with vehicle ( $p$-values $>0.05$; Fig. 1B-E).

We performed a similar series of experiments to examine the effects of these drugs on long-term extinction of context fear with an identical pattern of results. One day after training with three unsignaled footshocks in a novel context, extinction was induced by placing the mice in the feared context for 0,20 , 40 , or 60 continuous minutes. Retention control mice were given vehicle or drug injections on Day 2 and returned to their home cages. Again, in the absence of context exposure, Day 2 drug injections had no effect on freezing during the final test $\left(F_{(2,21)}=0.08, p=0.92\right.$; Fig. $2 \mathrm{~A})$. Freezing differed between the extinction mice. 


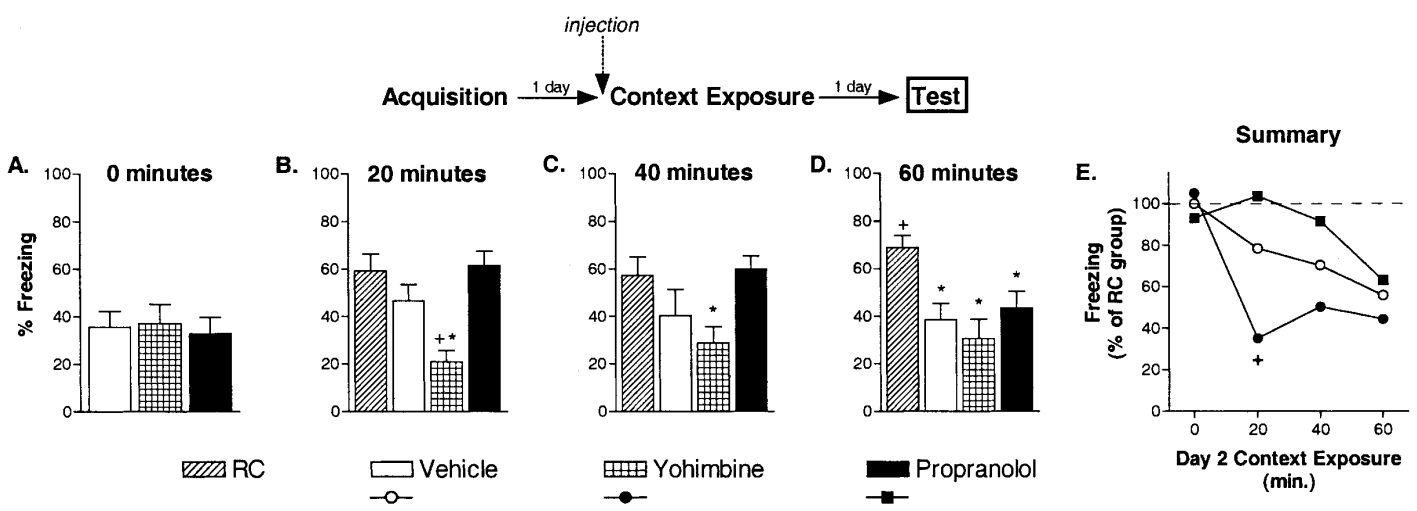

Figure 2 Yohimbine facilitates long-term context fear extinction. Separate experiments examined the effects of vehicle, yohimbine, and propranolol on extinction with $0(A), 20(B), 40(C)$, or $60(D)$ min of context exposure (eight to 12 mice/group). The data shown represent freezing during a single 5 -min context exposure given $1 \mathrm{~d}$ after the extinction sessions (drug free). The final summary panel $(E)$ shows the results of the four experiments with fear normalized to freezing in groups of mice that were injected with vehicle and not exposed to the feared context on Day 2 (retention control mice, RC). (*) $p<0.05$ versus RC mice; $(+) p<0.05$ versus vehicle-extinction mice.

groups after context exposure during the final test: $20 \mathrm{~min}$ $\left(F_{(3,28)}=9.06, p<0.01\right) ; 40 \mathrm{~min}\left(F_{(3,28)}=3.41, p<0.05\right) ; 60 \mathrm{~min}$ $\left(F_{(3,44)}=6.05, p<0.01\right)$. As with cue fear, long-term extinction increased with the amount of context exposure on Day 2. Vehicle-treated mice receiving $60 \mathrm{~min}$ of context exposure on Day 2 froze significantly less than RC mice ( $p<0.05$; Fig. 2D), whereas 20 or $40 \mathrm{~min}$ of context of exposure did not lead to long-term extinction ( $p$-values $>0.05$; Fig. $2 \mathrm{~B}, \mathrm{C}$ ). Mice treated with yohimbine prior to the Day 2 context exposure froze significantly less than vehicle-treated mice when only $20 \mathrm{~min}$ of exposure was given on Day 2 ( $p<0.05$; Fig. $2 \mathrm{~B}$ ). Propranolol treatment had no significant effect on long-term extinction. Mice treated with propranolol never differed in their final freezing relative to vehicleextinction mice ( $p$-values $>0.05$; Fig. $2 \mathrm{~B}-\mathrm{D}$ ).

To begin examining whether adrenergic manipulation affects the acquisition or consolidation of extinction learning, we next rated freezing behavior during the Day 2 CS presentations, while mice were in the drugged state. For the cue fear extinction experiments, we rated freezing during the first five CSs. Because all the mice in each group were treated identically up to this point in the experiments, the data were combined to improve the power of the analysis (Fig. 3A). A similar analysis of combined data from the three context fear extinction experiments was conducted for the first 10 min of context exposure on Day 2 (Fig. 3B). In both cue and context extinction, the groups differed in total freezing and in rate of extinction by two-way ANOVA: cue fear extinction (group: $F_{(2,92)}=8.86, p<0.01$; time: $F_{(4,368)}=36.77$, $p<0.01$; group $\times$ trials: $\left.F_{(8,368)}=2.13, p<0.05\right)$; context fear extinction (group: $F_{(2,80)}=3.38, p<0.05$; time: $F_{(4,320)}=104.60$, $p<0.01$; group $\times$ time: $\left.F_{(8,320)}=4.60, p<0.01\right)$. There were no differences in freezing during the first CS of cue fear extinction $\left(F_{(2,93)}=2.09, p=0.13\right)$, suggesting that the drugs did not affect expression of fear and that freezing differences during the final test were not attributable to differential fear acquisition between the groups. This was also true of the first $2 \mathrm{~min}$ of exposure for context fear extinction $\left(F_{(2,80)}=0.12, p=0.89\right)$. Short-term extinction was evident in all groups of mice for both the cue and context experiments; freezing declined with increased exposure. For the cue fear experiments, overall freezing differed between all groups, with yohimbine showing the greatest short-term extinction (Fig. 3A). Post hoc contrasts for group were as follows: vehicle versus yohimbine $\left(F_{(1,92)}=17.71, p<0.01\right)$, vehicle versus propranolol $\left(F_{(1,92)}=4.07, p<0.05\right)$, yohimbine versus propranolol $\left(F_{(1,92)}=4.65, p<0.05\right)$. In the context fear experiments, freezing was similar for vehicle- and propranolol-treated mice; however, yohimbine-treated mice froze significantly less during the early portion of the extinction session (Fig. 3B). Post hoc contrasts for group were as follows: vehicle versus yohimbine $\left(F_{(1,80)}=5.65, p<0.05\right)$, vehicle versus propranolol $\left(F_{(1,80)}=0.07\right.$, $p=0.80)$, yohimbine versus propranolol $\left(F_{(1,80)}=4.39, p<0.05\right)$.

We next attempted to directly address whether or not adrenergic activity modulates the consolidation of extinction memories. Although the acute effects of yohimbine during the extinction session suggested a role in extinction memory acquisition, it remains possible that some consolidation of this memory occurred during the long session and yohimbine enhanced this process. We conducted two separate cue fear experiments with either 10 or 20 massed CSs given on Day 2. All mice (except the RC group) were extinguished in the drug-free state
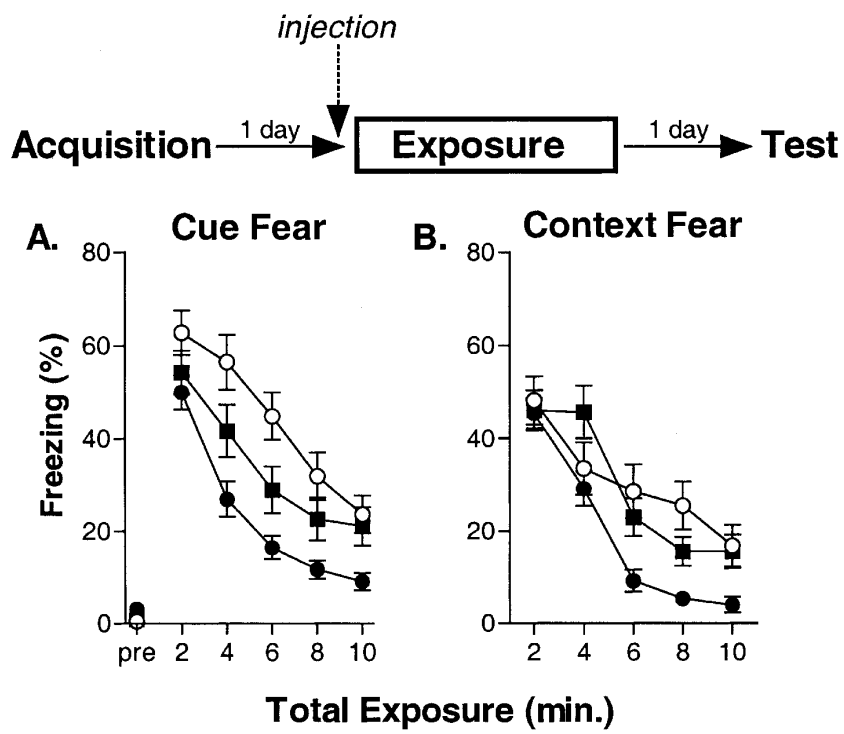

\section{-O-Vehicle $\rightarrow$-Yohimbine $\rightarrow$-Propranolol}

Figure 3 Yohimbine facilitates extinction of cue and context fear acutely. CS-elicited freezing during the Day 2 extinction sessions from all of the experiments shown in Figures 1 and 2, 20 min after injection of vehicle, yohimbine, or propranolol (27-32 mice/group). Because mice were treated identically up to the fifth CS of the cue fear experiments $(A)$ and the tenth minute of exposure in the context fear experiments $(B)$, the data were combined for this analysis. 
and injected with drug or vehicle immediately after the extinction session. Again, freezing in response to a single CS presentation was assessed on Day 3 to measure long-term extinction (Fig. 4). Freezing prior to the test CS was minimal for all groups. There were no statistically significant group differences in either of these experiments during the test CS (10 CS experiment: $F_{(3,28)}=1.49, p=0.24 ; 20$ CS experiment: $\left.F_{(3,28)}=2.23, p=0.11\right)$. In each experiment, mice exposed to nonreinforced CSs on Day 2 froze slightly less than RC mice; however, the degree of freezing in these groups was unaffected by postextinction drug injections.

\section{Spaced Extinction and Adrenergic Manipulation}

Previous studies (Cain et al. 2003) led us to hypothesize that nonreinforced CS presentations recruit two opposing mechanisms: fear extinction and fear incubation. The pattern of those results suggested that massed CS presentations favor fear extinction, whereas spaced CS presentations favor fear incubation. Although fear incubation was never observed to persist long term in those behavioral studies, mice failed to show long-term extinction when multiple CS presentations were temporally spaced. We wondered whether manipulating the adrenergic system might tip the scales in favor of either extinction or incubation with spaced CSs. To examine this, we injected mice with drug or vehicle and exposed them to seven CSs separated by $20 \mathrm{~min}$ on Day 2. Because ceiling and floor effects made it difficult to detect persistent freezing increases and decreases in the same experiment, we conducted two separate experiments with either a weak or strong acquisition protocol on Day 1. As before, freezing was assessed with a single CS presentation on Day 3; however, in these studies the final test CS was 5 min long. Pilot studies revealed that this extended test CS improved our ability to detect subtle differences between experimental groups.

Freezing was rated during both the Day 2 CS exposure and Day 3 test sessions. For the first experiment, mice received a weaker acquisition protocol on Day 1. Prior to the first Day 2 CS presentation, freezing was minimal for all groups. Patterns of freezing across the seven CS presentations on Day 2 differed between the groups. There was a nonsignificant trend for a group difference in freezing during the first CS of this exposure session $\left(F_{(2,21)}=3.35, p=0.06\right.$; Fig. 5A). Post hoc contrasts revealed no significant differences between the groups during the first CS exposure ( $p$-values $>0.05)$. No evidence of extinction (reduced freezing) was seen in any group. In fact, all groups showed some increased freezing (incubation) with repeated, spaced CS exposures. The main effects of the two-way ANOVA were as follows: group $\left(F_{(2,21)}=9.70, p<0.01\right)$, trials $\left(F_{(6,126)}=5.07, p<0.01\right)$, group $\times$ trials $\left(F_{(12,126)}=0.96, p=0.47\right)$. The drugs had pronounced effects on the pattern of freezing during the spaced CS session. Propranolol tended to enhance incubation, although overall freezing levels were not statistically greater than vehicletreated mice, possibly because of a ceiling effect (post hoc contrast for vehicle vs. propranolol: $\left.F_{(1,21)}=3.53, p=0.07\right)$. Yohimbine significantly reduced incubation; overall freezing levels were less than vehicle-treated mice (post hoc contrast for group: $\left.F_{(1,21)}=6.30, p<0.05\right)$. A similar pattern was observed during the Day 2 session of the second experiment, in which a stronger acquisition protocol was used (Fig. 5C). Freezing was minimal prior to the first CS exposure for all groups. However, in this experiment, mice treated with yohimbine froze significantly less than vehicle-treated mice during the first exposure CS (group: $F_{(2,21)}=7.92, p<0.05$; post hoc contrast for vehicle vs. yohimbine $[p<0.01]$; for vehicle vs. propranolol $[p>0.05])$. Again, there was no evidence for extinction in any of the groups, and all groups showed increased freezing with repeated spaced CSs. The main effects for the twoway ANOVA were as follows: group $\left(F_{(2,21)}=21.36, p<0.01\right)$, trials $\left(F_{(6,126)}=12.22, p<0.01\right)$, group $\times$ trials $\left(F_{(12,126)}=2.75, p<0.01\right)$. Again, ceiling effects may have prevented detection of a significant enhancement of incubation with propranolol (post hoc contrast for vehicle vs. propranolol groups: $F_{(1,21)}=0.56, p=0.46$ ), yohimbine again reduced the overall amount of fear incubation with the spaced exposure protocol (post hoc contrast for vehicle vs. yohimbine groups: $\left.F_{(1,21)}=27.56, p<0.01\right)$. During the drug-free Day 3 test sessions, freezing was minimal for all groups of mice prior to the test CS. Significant differences in freezing during the test CS were observed for both experiments: weak cue fear $\left(F_{(3,28)}=5.36, p<0.01\right.$; Fig. 5B), strong cue fear $\left(F_{(3,28)}=5.15, p<0.01\right.$; Fig. $\left.5 D\right)$. Consistent with previous experiments (Cain et al. 2003), the acute fear incubation observed on Day 2 did not persist to the Day 3 test in either experiment for vehicle-treated mice ( $p$-values $>0.05$ for RC vs. vehicle post hoc contrasts in each experiment). Freezing was near floor in the weak cue fear experiment for the RC, vehicle, and yohimbine groups, possibly obscuring any net extinction in the yohimbine group ( $p>0.05$ for vehicle vs. yohimbine). Interestingly, propranolol treatment during the spaced CS session led to a persistent incubation of cue fear compared with vehicle and RC mice ( $p$-values $<0.05)$. In the strong cue fear experiment, freezing was near ceiling for the RC, vehicle, and propranolol groups, possibly obscuring any net incubation in the propranolol group $(p>0.05$ for vehicle vs. propranolol). However, in this experiment, mice treated with yohimbine during the Day 2 spaced CS session froze significantly less than vehicle-treated and RC mice during the final test CS $(p$-values $<0.05)$.

Figure 4 Yohimbine has no effect on cue fear extinction when injected immediately afte massed CS presentations. Separate experiments examined the effect of injecting vehicle, yohimbine, or propranolol after $10(A)$ or $20(B)$ massed CS presentations (eight mice/ group). The data shown represent freezing during a single 2-min CS given $1 \mathrm{~d}$ after the extinction sessions (drug free). Retention control (RC) mice received no CS presentations and were injected with vehicle on Day 2 .

\section{Learning \& Memory}



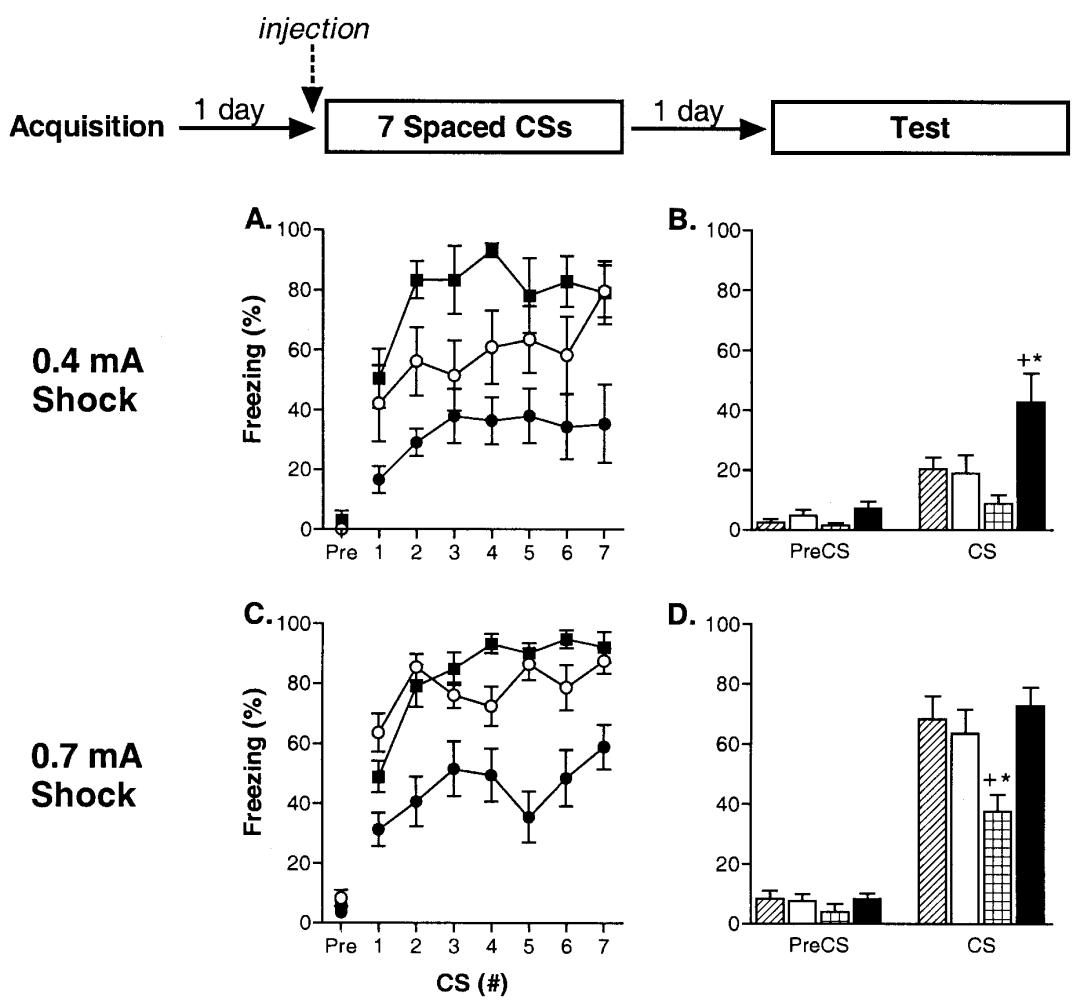

एII RC
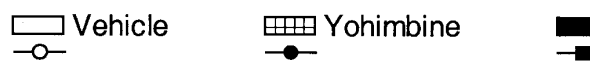

Propranolol

Figure 5 Yohimbine leads to extinction, whereas propranolol leads to incubation, of cue fear when given in conjunction with spaced CS presentations. Separate experiments examined the effect of vehicle, yohimbine, or propranolol on the effect of spaced CS presentations after weak ( $A, B$; see Materials and Methods) or strong ( $C, D$; see Materials and Methods) cue fear conditioning (eight mice/group). In each experiment, $1 \mathrm{~d}$ after acquisition, mice were injected with vehicle, yohimbine, or propranolol and presented with seven CSs (20 min ITI). $(A, C)$ Freezing during the spaced CS sessions 20 min after injections. $(B, D)$ Freezing $1 \mathrm{~d}$ later during the final 5 -min CS tests (drug free). $\left(^{*}\right) p<0.05$ versus RC mice; $(+) p<0.05$ versus vehicleexposure mice.

\section{Spontaneous Locomotor Activity and Adrenergic Manipulation}

In the last experiment, we examined the effects of yohimbine and propranolol on gross locomotor activity to determine if the drugs affected freezing indirectly by influencing the competing tendency to move. Mice were injected with drug or vehicle and placed in a novel chamber for $60 \mathrm{~min}$. The total distance traveled in arbitrary units was recorded in 10-min blocks (Fig. 6). There were no differences in gross locomotor activity for any of the groups, and all groups showed some habituation during the session. Results of the two-way ANOVA were as follows: group $\left(F_{(2,21)}=0.90, p=0.42\right)$; time $\left(F_{(5,105)}=17.79, p<0.01\right)$; group $\times$ time $\left(F_{(10,105)}=1.88, p=0.13\right)$.

\section{DISCUSSION}

We recently reported that temporal massing of CS presentations improves the efficiency of both short- and long-term fear extinction (Cain et al. 2003). Shorter inter-CS intervals (5 sec) led to rapid and profound extinction, whereas longer inter-CS intervals (20 $\mathrm{min})$ produced no acute extinction, and even increased freezing. When tested a day or a week after the nonreinforced CS presentations, massed CSs led to persistent extinction, whereas spaced CSs produced no extinction. We hypothesized that CS presentations trigger two opposing processes: (1) extinc-

tion, a reduction in conditional responding, and (2) incubation, an increase in conditional responding. Our data suggested that CS massing essentially isolated the extinction process, whereas CS spacing recruited both processes.

The present series of experiments was designed for three general purposes: first, to continue an investigation into the molecular mechanisms of fear extinction; second, to test the hypothesis that CS presentations trigger opposing extinction and incubation processes; and third, to model the interaction between pharmacotherapy and behavior therapy. We discuss these topics sequentially below.

Several lines of evidence suggest that adrenergic activity is likely to play a role in fear extinction. Adrenergic activity can promote consolidation of emotional memories, a mechanism that might enhance extinction, fear incubation, or both (Cahill et al. 1994, 2000; Nielson and Jensen 1994; Izquierdo and Medina 1995). On the other hand, adrenergic activity has been implicated in the mediation of anxiety (Tanaka et al. 2000). If adrenergic activity relays a danger signal when a fear-eliciting CS is presented, it is difficult to predict the result of manipulating this signal. Increased adrenergic activity should make CSs more aversive, which might enhance extinction if the key event in inducing this memory is a mismatch between what is expected and what occurs (as in the RescorlaWagner model; Rescorla and Wagner 1972). However, if incubation is related to the aversiveness of the CS, and competes with extinction, then more adrenergic activity may enhance incubation and impair extinction (Eysenck 1968; Cain et al. 2003). Decreasing adrenergic activity would also lead to conflicting predictions for the same reasons. Thus, the complicated role of norepinephrine in both memory and anxiety makes it difficult to predict the effects of manipulating adrenergic tone during fear extinction.

Rather than make an explicit prediction, we decided to manipulate adrenergic activity in both directions and examine the effects on fear extinction. Our first experiments (Figs. 1-4) used massed CSs to best isolate the extinction process. Yohimbine, an autoinhibitory $\alpha_{2}$-receptor antagonist, was used to increase adrenergic activity. Propranolol, a $\beta$-receptor antagonist, was used to reduce adrenergic effects. The opposing effects of these drugs on the adrenergic system and anxiety are well-documented in both animals and humans (Davis et al. 1979; Brantigan et al. 1982; Hartley et al. 1983; Durel et al. 1986; Turner 1991; Albus et al. 1992; Gao and Cutler 1992; Bremner et al. 1996a,b; Rex et al. 1998).

We found that extinction of both cue and context conditional fear is facilitated by yohimbine. Acutely, during CS presentations while the drug was on board, yohimbine-treated mice extinguished faster. In addition, when tested the next day drugfree, yohimbine reduced the total number of Day 2 CS presentations necessary to achieve long-term extinction. These results were not due to effects on locomotor activity or fear expression as yohimbine did not alter freezing during the first extinction CS or during a test of spontaneous locomotor activity. It is also important to point out that with enough extinction (30 CSs or $60 \mathrm{~min}$ of context exposure; Figs. 1 and 2), yohimbine had no detectable 


\section{Locomotor Activity}

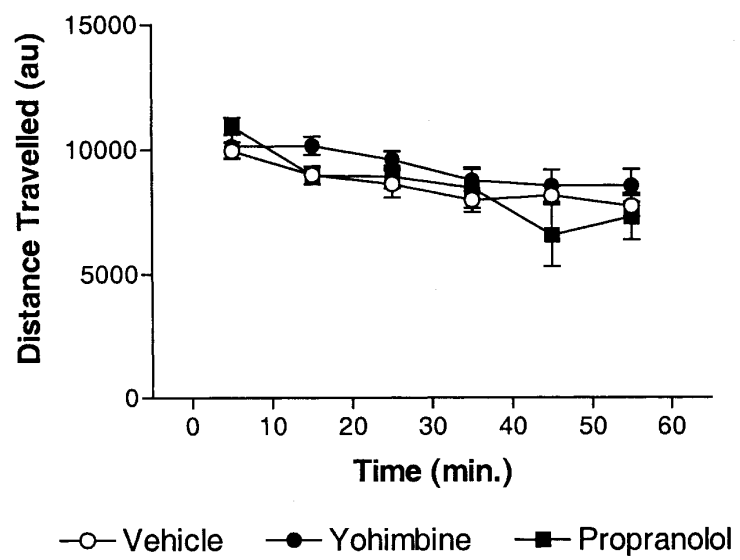

Figure 6 No effect of yohimbine or propranolol on gross locomotor activity. Separate groups of mice were injected with vehicle, yohimbine, or propranolol $20 \mathrm{~min}$ before placement in a novel chamber (eight mice/ group). The total distance traveled was monitored by an automated system and expressed in arbitrary units.

effect on long-term extinction. Also, it is notable that propranolol had no significant effect on extinction with the massed protocols. These findings suggest that the adrenergic system modulates, but is not required for, fear extinction, and that the contribution it makes during massed extinction is minimal These findings are consistent with a substantial literature showing that lesions of the adrenergic dorsal forebrain bundle or locus coeruleus prevent extinction of aversive memories, including inhibitory avoidance and eyeblink conditioning (Mason and Fibiger 1979; McCormick and Thompson 1982), and that propranolol inhibits extinction of conditioned taste aversion (CTA; Mason and Fibiger 1979; Bahar et al. 2003), because the protocols used for extinction in these experiments may be characterized as "spaced."

Another paper from the Dudai group has several intriguing parallels to the work described in this paper (Berman et al. 2003). They found that there was considerable latency after extinction training $(\sim 2 \mathrm{~h})$ before the expression of extinction, and demonstrated that the CS exposure alone could be shown to be aversive, a parallel of the incubation effects we see with spaced training. In that protocol, propranolol blocked the expression of extinction, apparently by extending this latency period. They also showed that a "massed" extinction procedure, involving several extinction trials in a single day, caused profound extinction, but also showed substantial spontaneous recovery day to day. Interestingly, propranolol had no effect on this recovery, thus having no effect on massed extinction, but clenbuteral, a $\beta$-adrenergic agonist, blocked the spontaneous recovery, and thus yielded greater long-term extinction. Thus, even in the very different aversive protocol of CTA, the adrenergic system seems to play a very similar role to that we have shown for fear conditioning.

We next assessed the role of the adrenergic system in learning during spaced CS presentations, a protocol that we believe recruits both extinction and incubation processes. As in our previous studies, spaced CS presentations produced no short- or long-term extinction in vehicle-treated animals. In fact, vehicletreated mice froze more with successive CS presentations. Propranolol treatment led to increased freezing acutely, whereas yohimbine significantly attenuated this increase. During the final drug-free test, vehicle-treated mice showed no evidence of longterm extinction (relative to retention controls). Interestingly, propranolol led to a persistent incubation of cue fear, whereas yohimbine produced extinction with the spaced protocol.

The findings from the spaced CS experiments are the clearest evidence in our hands that CS presentations recruit opposing extinction and incubation mechanisms. Initially, it was quite surprising that delivery of multiple nonreinforced CS presentations led to no long-term behavioral change. However, it appears that with sufficiently spaced CSs, extinction and incubation balance each other out, resulting in no net behavioral change. Because the first experiments in this paper suggest that adrenergic activity promotes extinction, we believe the spaced CS experiments can be interpreted in terms of changes in the likelihood of extinction. Propranolol, which had no significant effect on extinction, led to persistent incubation in the spaced protocol. Yohimbine generated extinction even with the spaced protocol. Thus, enhancing adrenergic activity appears to tip the scales in favor of extinction, whereas impairing adrenergic activity appears to tip the scales in favor of incubation. Because propanolol only has an effect on incubation, it may be that the major role of adrenergic activity is to suppress the incubation mechanism. However, it is also possible that the adrenergic system positively modulates extinction, which competes with incubation, but through a $\beta$-receptor-independent mechanism.

We also attempted to ask whether adrenergic activity modulates extinction acquisition or consolidation of this memory. As mentioned earlier, although the adrenergic system has a long history in anxiety research, it is also well known to affect memory consolidation. That is, enhancing adrenergic transmission improves memory recall even when the manipulation occurs after training (McGaugh 2000). Several of our observations suggest that a simple effect of yohimbine and propranolol on extinction memory consolidation cannot account for our results. First, yohimbine did not enhance the memory for fear incubation, despite acting generally to increase fear and memory. Second, propranolol, an amnestic and anxiolytic compound, accelerated increases of freezing during spaced CS exposures, and promoted the memory of that increase on Day 3. Finally, neither drug had any effect on long-term extinction, when administered immediately after 20 or 10 CS presentations (Fig. 4). On the other hand, when the drug was on board, during the nonreinforced CS presentations, the drugs had significant effects on freezing (Fig. 3). Propranolol generated more freezing during CS presentations, whereas yohimbine clearly increased the rate of extinction, starting from the first presentation of the cue, and by the fifth minute of context exposure. Taken together, these findings suggest that the adrenergic system modulates extinction learning, rather than consolidation. However, we cannot rule out the possibility that some memory consolidation occurs during the CS presentation sessions and the adrenergic system modulates this fast consolidation. Interestingly, some have suggested that adrenergic activity promotes memory formation by signaling novelty (Sara et al. 1994, 1995), not necessarily emotionality, a notion that is also consistent with our observed drug effects, assuming that, after learning of the CS-US association, nondelivery of the expected US is more novel than reactivating the contingent CS-US association with brief exposures.

The data in this paper are consistent with our previous finding that the extinction of fear is more efficient when training trials are massed rather than temporally distributed. In addition, they show that the adrenergic system plays a role in whether the animal responds to CS-alone presentations with extinction or with incubation. In fact, they suggest that propranolol, a drug commonly used for the treatment of anxiety disorders, may be counterproductive when used in conjunction with behavior therapy for the same disorder. More importantly, it suggests that yohimbine may be a useful adjunct to such behavior therapy of

\section{4}


human anxiety disorders, despite being anxiogenic. Our data suggest that yohimbine may not only accelerate treatment when given with otherwise effective behavioral exposure protocols, but also, in some cases, convert ineffective exposures, like our temporally spaced CS presentation, into effective treatments. The fact that an anxiogenic drug facilitates extinction also lends support to the hypotheses that greater excitation during extinction leads to greater extinction (Rescorla 2000) and to the observation that effective treatment depends on generating a sufficient level of anxiety and sympathetic activation to induce effective behavioral extinction (Stampfl and Levis 1967).

\section{MATERIALS AND METHODS}

\section{Subjects}

Naive 12-20-wk-old C57/bl6 male mice (Taconic) were housed four per cage, maintained on a 12:12 light/dark schedule, and allowed free access to food and water. All testing was conducted during the light phase in illuminated testing rooms following protocols approved by UCLA's Institutional Animal Care and Use Committee.

\section{Drugs}

Yohimbine (5 mg/kg) and propranolol (10 mg/kg; Sigma) were dissolved in 10\% Cremophor EL (BASF)/PBS vehicle and injected subcutaneously (s.c.) 20 min prior to behavioral testing in a 10 $\mathrm{mL} / \mathrm{kg}$ volume.

\section{Conditioning Apparatus}

Two contexts (A and B), in separate rooms, were used for all behavioral testing. Shuttle box compartments (\#ENV-010MC; Med Associates) measuring $20.3 \times 15.9 \times 21.3 \mathrm{~cm}$ served as context A, and conditioning boxes (\#ENV-008; Med Associates) measuring $30.5 \times 24.1 \times 21 \mathrm{~cm}$ served as context B. Both contexts $\mathrm{A}$ and $\mathrm{B}$ had transparent front and back walls and stainless steel grid floors ( $3.2 \mathrm{~mm}$ diameter, $8 \mathrm{~mm}$ centers). Context A was wiped down before testing with $10 \%$ ethanol and context $\mathrm{B}$ with $10 \%$ methanol. Individual video cameras were mounted in the ceiling of each chamber and connected via a quad processor to a standard VCR and monitor for videotaping and scoring of freezing. Grid floors were connected to a scrambled shock source (ENV-412 and ENV-413; Med Associates). Auditory stimuli (ANL926; Med Associates) were delivered via a speaker in the chamber wall. Delivery of stimuli was controlled with a PC and Med-PC software through a SmartCTL Interface System (DIG-716; Med Associates). Background white noise was maintained at $62 \mathrm{~dB}$ throughout behavioral testing.

\section{Behavioral Testing}

All fear experiments comprised three phases: (1) fear acquisition, (2) unpaired CS presentations, and (3) testing. Each phase was separated from the preceding by $1 \mathrm{~d}$ to allow for memory consolidation. Acquisition of cue fear took place in context A, whereas context fear acquisition occurred in context B. All CS presentation and testing sessions occurred in context B. Fear acquisition was always conducted in the drug-free state, and mice were assembled into matched experimental groups based on postshock freezing. In cue fear experiments, all CSs were 2-min, 80 -dB white-noise presentations. In all experiments, the USs were 2-sec scrambled footshocks. CS presentation sessions usually occurred after injections of drug or vehicle. Freezing behavior was rated by an experienced investigator, who was blinded to treatment classification of the mice, using a 5-sec instantaneous time sampling technique (12 observances/min). Each experiment included a retention control (RC) group, which received identical acquisition training and testing sessions, but no CS presentations on Day 2, for comparison with the treatment groups.

\section{Adrenergic Manipulation During Massed CS Exposure: Cue Fear}

Five separate experiments examined the effects of adrenergic manipulation on extinction learning during $0,5,10,20$, or 30 CS presentations. For acquisition, all mice received two pairings of the CS with coterminating $0.7-\mathrm{mA}$ footshocks $(2 \mathrm{~min}$ intertrial interval, ITI), and 2-min stimulus-free periods preceded and followed the pairings. For extinction, mice received $0,5,10$, 20, or 30 2-min CS exposures (5s ITI) after pretreatments with drug or vehicle. Retention control mice were injected with vehicle and placed in context B for the same duration as extinguished mice but received no CS presentations. The final tests consisted of a 2-min acclimation period followed by a single, continuous, 2-min, 80-dB white-noise presentation.

\section{Adrenergic Manipulation During Massed CS Exposure: Context Fear}

Separate experiments examined the effects of adrenergic manipulation during $0,20,40$, or 60 total minutes of massed context exposure. During acquisition, all mice received three $0.7-\mathrm{mA}$ unsignaled footshocks ( 2 min ITI); 2 -min and 4-min stimulus-free periods preceded and followed the shocks. Massed exposure involved $0,20,40$, or 60 continuous minutes of re-exposure to the context for all treatment groups after drug or vehicle injections. Retention control mice were injected with vehicle or drugs and returned to their home cage on Day 2. Single, continuous 5-min context exposures constituted the final tests.

\section{Adrenergic Manipulation During Spaced CS Exposure: Weak Cue Fear}

For acquisition, all mice received two pairings of the CS with 0.4-mA footshocks ( $2 \mathrm{~min} \mathrm{ITI),} \mathrm{and} \mathrm{2-min} \mathrm{stimulus-free} \mathrm{periods}$ preceded and followed the pairings. Treatment groups received seven 2-min CS exposures (20 min ITI) after pretreatments with drug or vehicle. Retention control mice were injected with vehicle and placed in context B for the same duration as experimental mice, but received no CS exposures. The final test consisted of a 2-min acclimation period followed by a single, continuous, 5-min, 80-db white-noise presentation.

\section{Adrenergic Manipulation During Spaced CS Exposure: Strong Cue Fear}

For acquisition, all mice received two pairings of the CS with 0.7-mA footshocks ( 2 min ITI), and 2-min stimulus-free periods preceded and followed the pairings. Treatment groups received seven 2-min CS exposures (20 min ITI) after pretreatments with drug or vehicle. Retention control mice were injected with vehicle and placed in context B for the same duration as experimental mice, but received no CS exposures. The final test consisted of a 2-min acclimation period followed by a single, continuous, 5-min, 80-db white-noise presentation.

\section{Adrenergic Manipulation After Massed CS Exposure: Cue Fear}

Two separate experiments examined the effect of drug injections given after massed CS exposure. For acquisition, all mice received two pairings of the CS with coterminating 0.7-mA footshocks (2 min ITI); 2-min stimulus-free periods preceded and followed the pairings. Treatment groups received 10 or 202 -min CS exposures ( 5 sec ITI) and were injected with drug or vehicle immediately afterward. Retention control mice were placed in context B for the same duration as extinguished mice, but received no CS presentations, and were injected with vehicle immediately afterward. The final tests consisted of a 2-min acclimation period followed by a single, continuous, 2-min, 80-dB white-noise presentation.

\section{Spontaneous Locomotor Activity}

Following drug injections (same drugs, doses, and pretreatments as fear experiments), naive mice were placed in novel illuminated open-field chambers (San Diego Instruments, $41 \times 41 \times 38 \mathrm{~cm}$ ) and allowed to explore freely for $60 \mathrm{~min}$. The total distance traveled (in arbitrary units) was monitored and analyzed with a PolyTrack video system on a standard PC using CRT402 software (San Diego Instruments). 


\section{Statistical Analyses}

Percent freezing scores were calculated by dividing the instances of freezing observed by the total observations and multiplying by 100 . All data represent mean freezing percentages $( \pm$ SEM) for groups of mice during specified time bins. The total session means and initial CS exposures were analyzed with one-way ANOVA and post hoc Dunnett's Test comparisons (when main effects were significant). Time course data were analyzed with two-way ANOVA. Differences were considered significant if $p<0.05$.

\section{ACKNOWLEDGMENTS}

The authors thank Alcino Silva, Michael Fanselow, Tom O'Dell, Bill Godsil, and Kelsey Martin for helpful comments on this manuscript. This work was supported by grants from the West Coast College of Biological Psychiatry, NARSAD, and the NIMH, and from an NIH NRSA grant to C.K.C.

The publication costs of this article were defrayed in part by payment of page charges. This article must therefore be hereby marked "advertisement" in accordance with 18 USC section 1734 solely to indicate this fact.

\section{REFERENCES}

Albus, M., Zahn, T.P., and Breier, A. 1992. Anxiogenic properties of yohimbine. I. Behavioral, physiological and biochemical measures. Eur. Arch. Psychiatry Clin. Neurosci. 241: 337-344.

Bahar, A., Samuel, A., Hazvi, S., and Dudai, Y. 2003. The amygdalar circuit that acquires taste aversion memory differs from the circuit that extinguishes it. Eur. J. Neurosci. 17: 1527-1530.

Baker, J.D. and Azorlosa, J.L. 1996. The NMDA antagonist MK-801 blocks the extinction of Pavlovian fear conditioning. Behav. Neurosci. 110: $618-620$.

Barela, P.B. 1999. Theoretical mechanisms underlying the trial-spacing effect in Pavlovian fear conditioning. J. Exp. Psychol. Anim. Behav. Process 25: 177-193.

Baum, M. 1988. Spontaneous recovery from the effects of flooding (exposure) in animals. Behav. Res. Ther. 26: 185-186.

Berman, D.E., Hazvi, S., Stehberg, J., Bahar, A., and Dudai, Y. 2003. Conflicting processes in the extinction of conditioned taste aversion: Behavioral and molecular aspects of latency, apparent stagnation, and spontaneous recovery. Learn. Mem. 10: 16-25.

Blanchard, R.J. and Blanchard, D.C. 1969. Passive and active reactions to fear-eliciting stimuli. J. Comp. Physiol. Psychol. 68: 129-135.

Bolles, R.C. and Fanselow, M.S. 1980. A perceptual-defensive-recuperative model of fear and pain. Behav. Brain Sci. 3: 291-323.

Bouton, M.E. and King, D.A. 1983. Contextual control of the extinction of conditioned fear: Tests for the associative value of the context. $J$ Exp. Psychol. Anim. Behav. Process 9: 248-265.

Brantigan, C.O., Brantigan, T.A., and Joseph, N. 1982. Effect of $\beta$ blockade and $\beta$ stimulation on stage fright. Am. J. Med. 72: 88-94.

Bremner, J.D., Krystal, J.H., Southwick, S.M., and Charney, D.S. 1996a. Noradrenergic mechanisms in stress and anxiety: I. Preclinical studies. Synapse 23: $28-38$.

1996b. Noradrenergic mechanisms in stress and anxiety: II. Clinical studies. Synapse 23: 39-51.

Cahill, L., Prins, B., Weber, M., and McGaugh, J.L. 1994. $\beta$-Adrenergic activation and memory for emotional events. Nature 371: 702-704

Cahill, L., Pham, C.A., and Setlow, B. 2000. Impaired memory consolidation in rats produced with $\beta$-adrenergic blockade. Neurobiol. Learn. Mem. 74: 259-266.

Cain, C.K., Blouin, A.M., and Barad, M. 2002. L-Type voltage-gated calcium channels are required for extinction, but not for acquisition or expression, of conditional fear in mice. $J$. Neurosci. 22: 9113-9121.

. 2003. Temporally massed CS presentations generate more fear extinction than spaced presentations. J. Exp. Psychology: Animal Behav. Processes 29: 323-333.

Cannon, W.B. 1963. Bodily changes in pain, hunger, fear and rage, 2nd ed. Harper \& Row, New York.

Carew, T.J. and Kandel, E.R. 1973. Acquisition and retention of long-term habituation in Aplysia: Correlation of behavioral and cellular processes. Science 182: 1158-1160.

Charney, D.S., Woods, S.W., Krystal, J.H., Nagy, L.M., and Heninger, G.R. 1992. Noradrenergic neuronal dysregulation in panic disorder: The effects of intravenous yohimbine and clonidine in panic disorder patients. Acta Psychiatr. Scand. 86: 273-282.

Craske, M.G. 1999. Anxiety disorders: Psychological approaches to theory and treatment. Westview Press, Boulder, CO.

Davis, M. 1992. The role of the amygdala in fear and anxiety. Annu. Rev. Neurosci. 15: 353-375.

Davis, M., Redmond Jr., D.E., and Baraban, J.M. 1979. Noradrenergic agonists and antagonists: Effects on conditioned fear as measured by the potentiated startle paradigm. Psychopharmacology (Berl) 65: $111-118$

Durel, L.A., Krantz, D.S., and Barrett, J.E. 1986. The antianxiety effect of $\beta$-blockers on punished responding. Pharmacol. Biochem. Behav. 25: $371-374$

Ebbinghaus, H. 1885/1913. Memory: A contribution to experimental psychology. Teachers College, Columbia University, New York.

Eysenck, H.J. 1968. A theory of the incubation of anxiety/fear responses. Behav. Res. Therapy 6: 309-321.

. 1979. The conditioning model of neurosis. Behav. Brain Sci. 2: 155-199.

Falls, W.A., Miserendino, M.J., and Davis, M. 1992. Extinction of fear-potentiated startle: Blockade by infusion of an NMDA antagonist into the amygdala. J. Neurosci. 12: 854-863.

Fanselow, M.S. and Tighe, T.J. 1988. Contextual conditioning with massed versus distributed unconditional stimuli in the absence of explicit conditional stimuli. J. Exp. Psychol. Anim. Behav. Process 14: $187-199$.

Fanselow, M.S., DeCola, J.P., and Young, S.L. 1993. Mechanisms responsible for reduced contextual conditioning with massed unsignaled unconditional stimuli. J. Exp. Psychol. Anim. Behav. Process 19: 121-137.

Ferry, B. and McGaugh, J.L. 1999. Clenbuterol administration into the basolateral amygdala post-training enhances retention in an inhibitory avoidance task. Neurobiol. Learn. Mem. 72: 8-12.

Frankland, P.W., Takahashi, E., Ohno, M., and Silva, A.J. 2002. Molecular mechanisms underlying extinction of conditioned fear Program No 779.1. Society for Neuroscience 2002 Abstract Viewer/Itinerary Planner.

Freudenthal, R., Locatelli, F., Hermitte, G., Maldonado, H., Lafourcade, C., Delorenzi, A., and Romano, A. 1998. к-B like DNA-binding activity is enhanced after spaced training that induces long-term memory in the crab Chasmagnathus. Neurosci. Lett. 242: 143-146.

Gao, B. and Cutler, M.G. 1992. Effects of acute and subchronic administration of propranolol on the social behaviour of mice; an ethopharmacological study. Neuropharmacology 31: 749-756.

Hartley, L.R., Ungapen, S., Davie, I., and Spencer, D.J. 1983. The effect of $\beta$ adrenergic blocking drugs on speakers' performance and memory. Br. J. Psychiatry 142: 512-517.

Huang, Y.Y. and Kandel, E.R. 1996. Modulation of both the early and the late phase of mossy fiber LTP by the activation of $\beta$-adrenergic receptors. Neuron 16: 611-617.

Huang, Y.H., Redmond Jr., D.E., Snyder, D.R., and Maas, J.W. 1975. In vivo location and destruction of the locus coeruleus in the stumptail macaque (Macaca arctoides). Brain Res. 100: 157-162.

Izquierdo, I. and Medina, J.H. 1995. Correlation between the pharmacology of long-term potentiation and the pharmacology of memory. Neurobiol. Learn. Mem. 63: 19-32.

Jefferson, J.W. 1996. Social phobia: Everyone's disorder? J. Clin. Psychiatry 57 Suppl 6: $28-32$.

Josselyn, S.A., Shi, C., Carlezon Jr., W.A., Neve, R.L., Nestler, E.J., and Davis, M. 2001. Long-term memory is facilitated by cAMP response element-binding protein overexpression in the amygdala. J. Neurosci. 21: 2404-2412.

Kogan, J.H., Frankland, P.W., Blendy, J.A., Coblentz, J., Marowitz, Z Schutz, G., and Silva, A.J. 1997. Spaced training induces normal long-term memory in CREB mutant mice. Curr. Biol. 7: 1-11.

LeDoux, J.E. 2000. Emotion circuits in the brain. Annu. Rev. Neurosci. 23: $155-184$.

Lu, K.T., Walker, D.L., and Davis, M. 2001. Mitogen-activated protein kinase cascade in the basolateral nucleus of amygdala is involved in extinction of fear-potentiated startle. J. Neurosci. 21: RC162.

Mason, S.T. and Fibiger, H. 1979. Noradrenaline, fear and extinction. Brain Res. 165: 47-56.

McCormick, D.A. and Thompson, R.F. 1982. Locus coeruleus lesions and resistance to extinction of a classically conditioned response: Involvement of the neocortex and hippocampus. Brain Res. 245: $239-249$.

McGaugh, J.L. 2000. Memory-A century of consolidation. Science 287: $248-251$

Nielson, K.A. and Jensen, R.A. 1994. $\beta$-Adrenergic receptor antagonist antihypertensive medications impair arousal-induced modulation of working memory in elderly humans. Behav. Neural. Biol. 62: $190-200$.

Redmond Jr., D.E., Huang, Y.H., Snyder, D.R., and Maas, J.W. 1976 Behavioral effects of stimulation of the nucleus locus coeruleus in the stump-tailed monkey Macaca arctoides. Brain Res. 116: 502-510. 
Rescorla, R.A. 2000. Extinction can be enhanced by a concurrent excitor. J. Exp. Psychol. Anim. Behav. Process 26: 251-260.

Rescorla, R.A. and Heth, C.D. 1975. Reinstatement of fear to an extinguished conditioned stimulus. J. Exp. Psychol. Anim. Behav. Process 1: 88-96.

Rescorla, R.A. and Wagner, A.R. 1972. A theory of Pavlovian conditioning: Variations in the effectiveness of reinforcement and nonreinforcement. In Classical conditioning II (eds. A.H. Black and W.F. Prokasy), pp. 64-99. Appleton-Century-Crofts, New York.

Rex, A., Voigt, J.P., Voits, M., and Fink, H. 1998. Pharmacological evaluation of a modified open-field test sensitive to anxiolytic drugs. Pharmacol. Biochem. Behav. 59: 677-683.

Sara, S.J., Vankov, A., and Herve, A. 1994. Locus coeruleus-evoked responses in behaving rats: A clue to the role of noradrenaline in memory. Brain Res. Bull. 35: 457-465.

Sara, S.J., Dyon-Laurent, C., and Herve, A. 1995. Novelty seeking behavior in the rat is dependent upon the integrity of the noradrenergic system. Brain Res. Cogn. Brain Res. 2: 181-187.

Sarvey, J.M., Burgard, E.C., and Decker, G. 1989. Long-term potentiation: Studies in the hippocampal slice. J. Neurosci. Methods 28: $109-124$

Schulz, B., Fendt, M., and Schnitzler, H.U. 2002. Clonidine injections into the lateral nucleus of the amygdala block acquisition and expression of fear-potentiated startle. Eur. J. Neurosci. 15: 151-157.

Southwick, S.M., Krystal, J.H., Morgan, C.A., Johnson, D., Nagy, L.M., Nicolaou, A., Heninger, G.R., and Charney, D.S. 1993. Abnormal noradrenergic function in posttraumatic stress disorder. Arch. Gen.
Psychiatry 50: 266-274.

Southwick, S.M., Bremner, J.D., Rasmusson, A., Morgan III, C.A., Arnsten, A., and Charney, D.S. 1999. Role of norepinephrine in the pathophysiology and treatment of posttraumatic stress disorder. Biol. Psych. 46: 1192-1204.

Stampfl, T.G. and Levis, D.J. 1967. Essentials of implosive therapy: A learning-theory-based psychodynamic behavioral therapy. J. Abnorm Psych. 72: 496-503.

Tanaka, M., Yoshida, M., Emoto, H., and Ishii, H. 2000. Noradrenaline systems in the hypothalamus, amygdala and locus coeruleus are involved in the provocation of anxiety: Basic studies. Eur. J. Pharmacol. 405: 397-406.

Tully, T., Preat, T., Boynton, S.C., and Del Vecchio, M. 1994. Genetic dissection of consolidated memory in Drosophila. Cell 79: 35-47.

Turner, P. 1991. Clinical psychopharmacology of $\beta$-adrenoceptor antagonism in treatment of anxiety. Ann. Acad. Med. Singapore 20: $43-45$.

Watson, J.B. and Rayner, P. 1920. Conditioned emotional reactions. J. Exp. Psychol. 3: 1.

Wolpe, J. 1969. The practice of behavior therapy. Pergamon Press, New York.

Wolpe, J. and Rowan, V.C. 1988. Panic disorder: A product of classical conditioning. Behav. Res. Ther. 26: 441-450.

Received October 2, 2003; accepted in revised form January 21, 2004. 


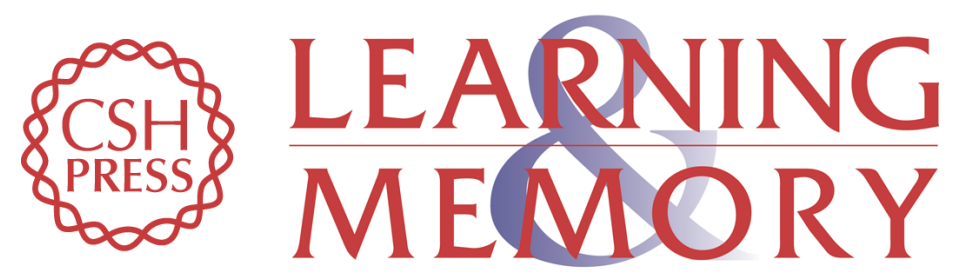

\section{Adrenergic Transmission Facilitates Extinction of Conditional Fear in Mice}

Christopher K. Cain, Ashley M. Blouin and Mark Barad

Learn. Mem. 2004, 11:

Access the most recent version at doi:10.1101/lm.71504

References

This article cites 53 articles, 8 of which can be accessed free at:

http://learnmem.cshlp.org/content/11/2/179.full.html\#ref-list-1

\section{License}

Email Alerting Service
Receive free email alerts when new articles cite this article - sign up in the box at the top right corner of the article or click here. 